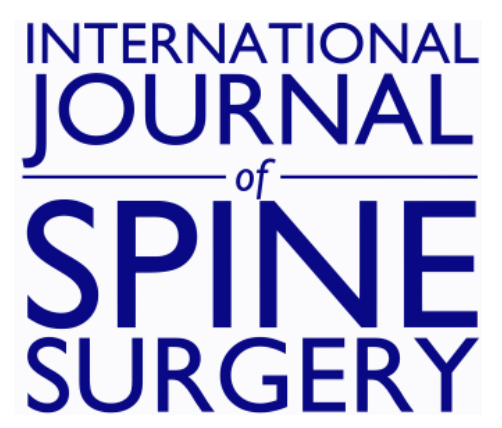

\title{
Changes in Segmental and Lumbar Lordosis After Lateral Lumbar Interbody Fusion With Different Lordotic Cage Angulations
}

Adewale A. Bakare, David R. Fessler, Joshua T. Wewel, Ricardo B. V. Fontes, Richard G. Fessler and John E. O'Toole

Int J Spine Surg 2021, 15 (3) 440-448

doi: https://doi.org/10.14444/8066

http://ijssurgery.com/content/15/3/440

This information is current as of April 26, 2023.

Email Alerts Receive free email-alerts when new articles cite this article. Sign up at:

http://ijssurgery.com/alerts

The International Journal of Spine Surgery

2397 Waterbury Circle, Suite 1,

Aurora, IL 60504, Phone: +1-630-375-1432 


\title{
Changes in Segmental and Lumbar Lordosis After Lateral Lumbar Interbody Fusion With Different Lordotic Cage Angulations
}

\author{
ADEWALE A. BAKARE, MD,${ }^{1}$ DAVID R. FESSLER, MD, PHD,${ }^{1}$ JOSHUA T. WEWEL, MD ${ }^{2}$ \\ RICARDO B. V. FONTES, MD, PHD,${ }^{1}$ RICHARD G. FESSLER, MD, PHD, ${ }^{1}$ JOHN E. O'TOOLE, MD, $\mathrm{MS}^{1}$ \\ ${ }^{I}$ Department of Neurosurgery, Rush University Medical Center, Chicago, Illinois, ${ }^{2}$ Piedmont Healthcare, Atlanta Brain and Spine, Atlanta, Georgia
}

\begin{abstract}
Background: Lateral lumbar interbody fusion (LLIF) affords a wide operative corridor to allow for a large interbody cage implantation for segmental reconstruction. There is a paucity of data describing segmental lordosis (SL) achieved with lordotic implants of varying angles. Here we compare changes in SL and lumbar lordosis (LL) after implantation of $6^{\circ}, 10^{\circ}$, and $12^{\circ}$ cages.

Methods: We retrospectively reviewed LLIF cases over a 5.5-year period. We derived SL and LL using the standard cobb angle measurement from a standing lateral radiograph. We analyzed mean changes in SL and LL over time using the linear mixed effect model to estimate these longitudinal changes.

Results: The most frequently treated level was L3 -4 , followed by L4 5 . Significant increases in mean SL were found at each follow-up time point for all the cohorts. In an intercohort comparison, the mean changes in SL at immediate postoperative and last follow-up were significantly greater in the $10^{\circ}$ cohort than $6^{\circ}\left(\left[7.4^{\circ}\right.\right.$ versus $\left.3.1^{\circ}, P=.004\right]$, [6.1 $1^{\circ}$ versus $2.3^{\circ}, P=.025$ ] respectively). The $12^{\circ}$ cohort had higher mean change in SL at last follow-up than the $6^{\circ}$ cohort $\left(5.9^{\circ}\right.$ versus $2.3^{\circ}, P=.022$ ). There was no difference in mean change in SL between the $10^{\circ}$ and $12^{\circ}$ cohorts. No difference in overall mean LL over time was found. In terms of mean change in LL, no difference was observed except at immediate and 6month postoperative in the $10^{\circ}$ cohort $\left(\left[9.6^{\circ}, P=.001\right]\right.$, [8.5, $\left.P=.003\right]$ respectively). By comparing mean change in LL, no difference existed except between the $10^{\circ}$ and $6^{\circ}$ immediately after surgery $\left(9.6^{\circ}\right.$ versus $\left.0.2^{\circ}, P=.006\right)$.
\end{abstract}

Conclusions: LLIF cages significantly improve SL at the index level. However, this increase in SL is greater for $10^{\circ}$ and $12^{\circ}$ cages than the standard $6^{\circ}$ cage. Use of $10^{\circ}$ cages also resulted in overall improved LL than $6^{\circ}$ cages.

Level of Evidence: 3.

Clinical Relevance: Lateral lumbar interbody fusion.

\section{Lumbar Spine}

Keywords: lateral lumbar interbody fusion, LLIF, segmental lordosis, SL, lumbar lordosis, LL, standard lordotic cages, transpsoas, cage dimension, cage angulation, $6^{\circ}$ cage, $10^{\circ}$ cage, $12^{\circ}$ cage

\section{INTRODUCTION}

Minimally invasive spine surgery has gained popularity in recent years owing to the advantages of less soft-tissue trauma, less postoperative pain, shorter hospital stays, fewer complications, and more rapid return to activities of daily living. In the literature, a variety of minimally invasive spine surgery approaches have been described such as anterior, posterior, and lateral approaches; each with its own advantages and disadvantages. Lateral lumbar interbody fusion (LLIF) utilizes a retroperitoneal transpsoas corridor to gain access to the anterior and lateral spinal column and disc space via a tubular retractor under fluoroscopic guidance. ${ }^{1-7}$
With direct access to the lateral aspect of the spine, there is a relative ease of implantation of interbody cages with wide and long footprints and with varying degrees of lordosis resulting in optimal segmental height restoration and concurrent indirect decompression of neural elements. ${ }^{1-7}$

Since it was first described by Ozgur et $\mathrm{al}^{8}$ in 2006, LLIF has evolved into a common and versatile procedure in the last decade. Its application has expanded from degenerative indications to include traumatic, neoplastic, deformity, and revision surgery indications in carefully selected patients. ${ }^{3-7,9,10}$ Although the advantages include large interbody footprint, restoration of disc/foraminal height, and restoration of sagittal and coronal 


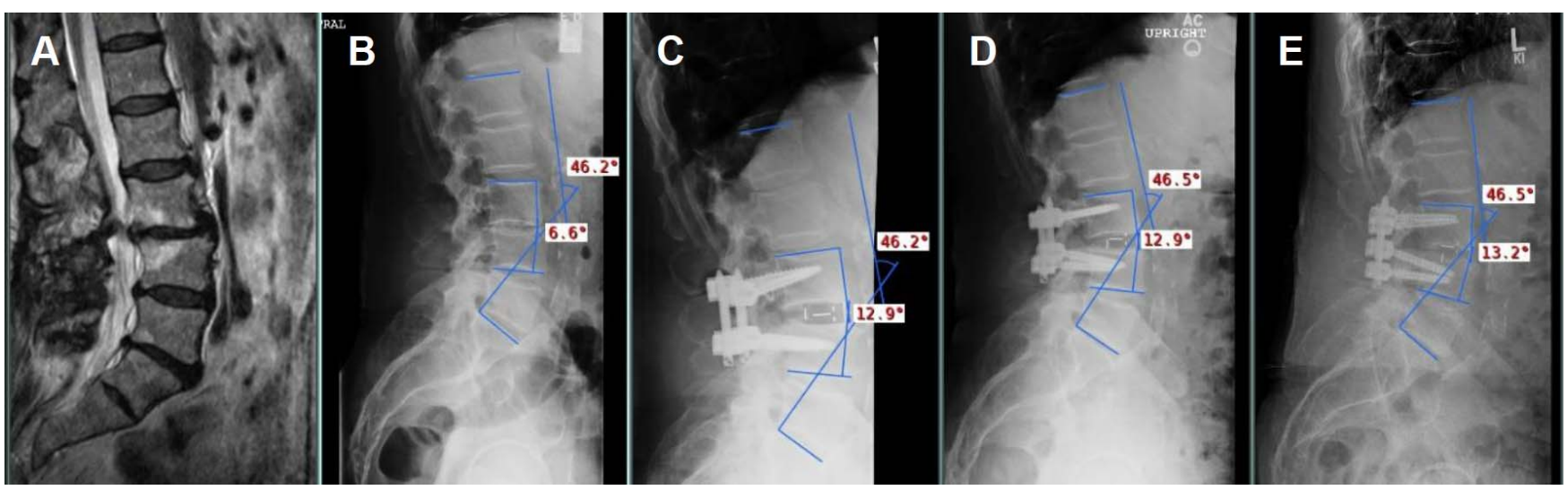

Figure 1. A 79-year-old male with prior right L3-4 microdiscectomy presents with persistent right L3 radiculopathy; the condition is due to severe spondylosis at L3-4 with retrolisthesis, disc collapse with modic endplate changes, and severe foraminal stenosis compressing right L3 nerve root. The patient underwent L3-4 interbody arthrodesis with a L50 $\times$ W22 $\times$ H13-mm $12^{\circ}$ lateral lumbar interbody fusion cage. (A) Preop magnetic resonance image showing the aforementioned findings. (B) Preop lateral upright radiograph showing initial $\mathrm{SL}=6.6^{\circ}$ at $\mathrm{L} 3-4$ level and $\mathrm{LL}=46.2^{\circ}$. (C-E) Postop lateral upright radiographs obtained after surgery $\left(\mathrm{SL}=12.9^{\circ}, \mathrm{LL}=\right.$ $\left.46.2^{\circ}\right)$, at the 6 -month follow-up $\left(\mathrm{SL}=12.9^{\circ}, \mathrm{LL}=46.5^{\circ}\right)$, and the last follow-up $\left(\mathrm{SL}=13.2^{\circ}, \mathrm{LL}=46.5^{\circ}\right)$, respectively.

alignment, several drawbacks described in literature include lumbar plexus injury especially at lower lumbar disc spaces, cage migration and/or subsidence, abdominal pseudohernia, vertebral body fractures, visceral injuries, and lack of access to the L5-S1 disc space due to anatomical constraints owing to the height of the iliac crest and lumbar plexus morphology. $1,3,6,7$

Although a variety of cage designs are available for use during LLIF, there is a paucity of data describing the degree of lordosis achieved relative to the lordosis of the implant. While analyzing the cage dimension (width, height, and length), many assume that postoperative lordosis achieved is close to the native lordosis of the implant; however, this is not always the case. Potential reasons for less than optimal lordotic correction include graft migration and/or subsidence. To our knowledge, no studies in the literature have compared and contrasted changes in global lumbar lordosis (LL) and segmental lordosis (SL) with respect to lateral interbody cages with varying lordotic angulations. To that end, we analyzed preoperative and postoperative lateral radiographs comparing the degree of lordotic correction among patients with lumbar degenerative disc disease receiving standard $6^{\circ}$ lordotic cage versus $10^{\circ}$ and $12^{\circ}$ lordotic cages. We hypothesized that the lateral lumbar interbody arthrodesis using the standard $6^{\circ}$ lordotic cage would result in less segmental lordotic correction than using the $10^{\circ}$ and $12^{\circ}$ lordotic cages.

\section{METHODS}

This research was reviewed and approved by the institutional review board at our institution. By searching our institutional electronic medical record database, we conducted a retrospective chart review of all transpsoas LLIF surgeries performed by the contributing authors (R.F., R.G.F., and J.O.) from January 1, 2013 to July 1, 2019. Three cohorts were identified based on whether they received $6^{\circ}, 10^{\circ}$, and/or $12^{\circ}$ cages. Preoperative (preop), immediate postoperative (postop), 6-month postop, and last follow-up lateral radiographs were evaluated. The last follow-up radiographs were obtained at averages of 17.2, 16.8, and 18.1 months from the preop radiographs for the $6^{\circ}, 10^{\circ}$, or $12^{\circ}$ cohorts, respectively. SL, LL, and other variables

(demographic and perioperative data) were recorded. LL is defined by the Cobb angle formed between the superior endplate of $\mathrm{S} 1$ and $\mathrm{L} 1$ as depicted in Figure 1B-E. SL is defined by the Cobb angle formed by the superior endplate of the vertebra above the index level and inferior endplate of the vertebra below the index level as illustrated in Figure 1B-E. These measurements were performed on standing upright lateral films.

Inclusion criteria included patients with ages ranging from 18 to 90 years old with degenerative disc disease and/or sagittal malalignment/coronal deformity that underwent 1 or more level LLIF with or without posterior spinal instrumented fusion using 1 or more $6^{\circ}, 10^{\circ}$, or $12^{\circ}$ cages or any combination of the cages with a minimum follow-up of 6 months. Exclusion criteria included individuals with infection or tumors, individuals with absent or poor preop or postop radiographs, or those with inadequate follow-ups as well as those receiving nonlordotic cages. Also excluded were individuals 
who underwent anterior column releases or levels that received hyperlordotic cages $\left(>12^{\circ}\right)$ and/or non-LLIF cages. Sixty-five patients met the inclusion criteria and were included for analyses.

\section{Surgical Technique}

LLIF was generally performed as previously described..$^{1-4,6,7,9,11-15}$ The patient was positioned in the lateral decubitus position on the operating table with a gentle flexion at the table "break" to open the flank for access to between the lower ribs and iliac crest.

Neurophysiologic monitoring was established with somatosensory and motor evoked potentials as well as free-running and evoked electromyography. Choice of interbody cage size and lordosis was surgeon-dependent based on patient anatomy and the objectives of surgery. The interbody cages were packed with various forms of synthetic allograft. The patient was then turned prone on a Jackson table to complete percutaneous posterior instrumentation with pedicle screws and rods via imageguided computer-assisted navigation or fluoroscopic guidance depending on the surgeon preference.

\section{Statistical Analysis}

Numeric data are presented as mean \pm standard deviation and range when deemed necessary. The statistical analyses of the longitudinal data were performed with the help of our Biostatistics Core group using the SAS 9.4 software. Linear mixed effect model was performed as previously described. ${ }^{16-20}$ Using the linear mixed effect model, we performed intracohort and intercohort analyses of SL and LL by cohort and time (preop, immediate postop, 6-month postop, and final follow-up). The main effects for time estimated the mean change in SL and LL from preop to immediate postop, 6month postop, and last follow-up. An interaction variable of cohort*time was included to measure the difference in change by cohort. The mixed effect model included a random intercept for a participant allowing us to account for person-to-person variability. Because the estimates were calculated by maximum likelihoods, this allowed all observed data (either unequal or equal) in each cohort to be used, so that each subject did not have to have all 4 observations (ie, data at preop, immediate postop, 6-month postop, and last follow-up). The linear mixed effect model was then used to estimate the mean SL and LL at each time point by cohort. $P$ value $<.05$ was deemed statistically significant.

We used time plots to depict the mean SL and LL at preop, immediate postop, 6-month postop, and final follow-up. We plotted estimated values from the model output (as denoted by the dots) with straight lines connecting them to help visualize the trend over time. The error bars illustrate $95 \%$ confidence interval (CI) around each estimate. We used a bar graph to illustrate the estimated mean changes in SL and LL at preop to immediate postop, 6-month postop, and last follow-up between the cohorts.

\section{RESULTS}

The average ages for the $6^{\circ}, 10^{\circ}$, and $12^{\circ}$ cohorts were $65.6,67.5$, and 64.8 years, respectively. The most treated level was L3-4, followed by L4 5 and L2-3. The rest of the demographic and perioperative data are summarized in Table 1. Out of a total of 32 patients (52 levels) who predominantly received $6^{\circ}$ cage LLIF, 14, 15, and 3 patients underwent 1-, 2-, and 3-level LLIF, respectively (Table 1). Also, 18 patients in this cohort underwent concurrent percutaneous instrumentation. In addition to LLIF with $6^{\circ}$ cages, 1 patient underwent concurrent L5-S1 anterior lumbar interbody fusion (ALIF), 2 patients underwent concurrent L4-S1 ALIF, and 1 patient underwent concurrent L5-S1 transforaminal lumbar interbody fusion (TLIF) (all these levels that received non-LLIF cages were excluded from analyses). Mean preop SL was observed to be $6.2^{\circ}$. The estimated mean immediate postop SL was $9.3^{\circ}$ with $3.1^{\circ}$ increase $\left(95 \% \mathrm{CI}: 1.3^{\circ}\right.$ $\left.4.9^{\circ} ; P=.001\right)$ from preop. At 6-month follow-up, estimated mean SL was $10.3^{\circ}$ with $4.1^{\circ}$ increase (95\% CI: $\left.2.3^{\circ}-5.9^{\circ} ; P=<.0001\right)$ from preop (Tables 2 and 3). At last follow-up, SL was $8.5^{\circ}$ with $2.3^{\circ}$ increase $\left(95 \% \mathrm{CI}: 0.4^{\circ}-4.2^{\circ} ; P=.021\right)$ from preop (Tables 2 and 3). There was no statistical difference in the value of $L L$ over time. LL was observed to be $40.3^{\circ}$ at preop, $40.5^{\circ}$ at immediate postop $\left(0.2^{\circ}\right.$ increase from preop, $95 \% \mathrm{CI}:-3.3^{\circ}$ to $3.8^{\circ} ; P=$ $.900), 42.6^{\circ}$ at 6 -month follow-up (2.3 increase from preop, $95 \% \mathrm{CI}:-1.4^{\circ}$ to $\left.6.0^{\circ} ; P=.218\right)$, and $43.4^{\circ}$ at last follow-up $\left(3.1^{\circ}\right.$ increase from preop, $95 \% \mathrm{CI}$ : $-0.8^{\circ}$ to $7.2^{\circ} ; P=.116$ ) (Tables 4 and 5 ).

The cohort receiving the $10^{\circ}$ cage consisted of 13 patients (30 levels) in Table 1. Four, two, two, four, and one patient(s) received 1-, 2-, 3-, 4-, and 5-level LLIF, respectively (Table 1). Ten patients under- 
Table 1. Summarized baseline demographic data and surgical data of all analyzed LLIF cases.

\begin{tabular}{|c|c|c|c|c|}
\hline Items & $6^{\circ}$ Cage $(n=32)$ & $10^{\circ}$ Cage $(n=13)$ & $12^{\circ}$ Cage $(n=20)$ & $P^{\mathbf{a}}$ \\
\hline 1. Sex, F:M & 14:18 & $6: 7$ & $9: 11$ & .988 \\
\hline 2. Age, mean $\pm \mathrm{SD}$ (range), y & $65.5 \pm 8.5(49-81)$ & $67.5 \pm 12.0(39-88)$ & $64.8 \pm 11.2(44-79)$ & .735 \\
\hline 3. Operation time, mean $\pm \mathrm{SD}$ (range), min & $245.0 \pm 109.7(86-499)$ & $323.9 \pm 147.7(140-494)$ & $202.3 \pm 81.8(73-360)$ & $.012^{\mathrm{b}}$ \\
\hline 4. EBL, mean $\pm \mathrm{SD}$ (range), $\mathrm{mL}$ & $89.1 \pm 100.3(10-450)$ & $173.5 \pm 180.4(30-600)$ & $83.8 \pm 75.0(5-300)$ & .117 \\
\hline 5. LOS, mean $\pm \mathrm{SD}$ (range), $\mathrm{h}$ & $85.6 \pm 54.2(24-216)$ & $178.8 \pm 204.2(48-812)$ & $104.7 \pm 63.2(23-216)$ & .164 \\
\hline \multicolumn{5}{|l|}{ 6. Preoperative diagnosis, $\mathrm{n}$ ( $\%$ of patients) } \\
\hline Spondylolisthesis & $15(45.5)$ & $5(38.5)$ & $9(45)$ & \multirow[t]{4}{*}{.991} \\
\hline Scoliosis & $8(24.2)$ & $5(38.5)$ & $6(30)$ & \\
\hline $\mathrm{DDD}$, foraminal stenosis & $6(18.2)$ & $2(15.4)$ & $3(15)$ & \\
\hline Revision surgery $^{\mathrm{c}}$ & $3(9.1)$ & $1(7.7)$ & $2(6.7)$ & \\
\hline \multicolumn{4}{|l|}{ 7. Levels treated, $n$ (of levels) ( $\%$ of patients) } & \multirow{6}{*}{$\begin{array}{c}P^{\mathrm{a}} \\
007^{\mathrm{b}} \\
000^{\mathrm{b}} \\
423\end{array}$} \\
\hline $\mathrm{T} 12-\mathrm{L} 1$ & 0 & $3(10.0)(23.1)$ & 0 & \\
\hline L1-2 & 0 & $5(16.7)(38.5)$ & 0 & \\
\hline L2-3 & $11(21.2)(33.3)$ & $7(23.3)(53.8)$ & $9(27.3)(45.0)$ & \\
\hline L3-4 & $24(46.2)(72.7)$ & $6(20.0)(46.2)$ & $11(33.3)(55.0)$ & \\
\hline L4-5 & $17(32.7)(51.5)$ & $9(30.0)(69.2)$ & $13(39.4)(65.0)$ & \\
\hline \multicolumn{4}{|l|}{ 8. Levels treated per case, n ( $\%$ of patient) } & $P$ \\
\hline 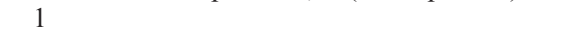 & $14(42.4)$ & $4(30.8)$ & $10(50.0)$ & \multirow[t]{5}{*}{$.008^{\mathrm{b}}$} \\
\hline 2 & $15(45.5)$ & $2(15.4)$ & $6(30.0)$ & \\
\hline 3 & $3(9.1)$ & $2(15.4)$ & $4(20.0)$ & \\
\hline 4 & 0 & $4(30.8)$ & 0 & \\
\hline 5 & 0 & $1(7.7)$ & 0 & \\
\hline
\end{tabular}

Abbreviations: DDD, degenerative disc disease; EBL, estimated blood loss; F, female; LLIF, lateral lumbar interbody fusion; LOS, length of stay; M, male; N, number. ${ }^{\text {a }} P$ values obtained from testing overall difference in the groups (items $1-5$ and 7 are different because the rows are not mutually exclusive; therefore, each variable/ subvariable will have its own $P$ value).

${ }^{\mathrm{b}}$ Statistical significance at $P<.05$.

${ }^{c}$ Revision surgery includes those with pseudoarthrosis, failed decompression, cage migration from prior interbody fusion, and adjacent level disease.

went concurrent percutaneous pedicle screw fixation, and 1 patient underwent laminectomy for further decompression. One patient underwent concurrent L5-S1 ALIF, 2 patients received concurrent $20^{\circ} \mathrm{LLIF}$ cages at L2-3, 1 patient received concurrent $20^{\circ}$ LLIF cage at L3-4, 1 patient received concurrent $25^{\circ}$ LLIF cage at L3-4, and 1 patient received concurrent $20^{\circ}$ LLIF cage at L4-5 (all these levels were excluded from the analysis). Mean SL at preop, immediate, 6-month, and last postop follow-ups were recorded as $7.8^{\circ}, 15.2^{\circ}$, $13.4^{\circ}$, and $13.9^{\circ}$, respectively, as illustrated in Table 2. From preop, there were $7.4^{\circ}$ increase $(95 \% \mathrm{CI}$ : $\left.5.1^{\circ}-9.8^{\circ} ; P=<.0001\right)$ in SL at immediate postop, $5.6^{\circ}$ increase $\left(95 \% \mathrm{CI}: 3.3^{\circ}-8.0^{\circ} ; P=<.0001\right)$ at $6-$ month follow-up, and $6.1^{\circ}$ increase $\left(95 \% \mathrm{CI}: 3.4^{\circ}-\right.$ $8.8^{\circ} ; P=<.0001$ ) at last follow-up (Table 3 ). Although there was significant change in LL from preop $\left(39.7^{\circ}\right)$ to immediate postop $\left(49.3^{\circ}, 9.6^{\circ}\right.$ increase, $\left.95 \% \mathrm{CI}: 4.0^{\circ}-15.1^{\circ} ; P=.001\right)$ and from preop to 6 -month postop $\left(48.2^{\circ}, 8.49^{\circ}\right.$ increase, $95 \%$

Table 2. Comparison of $\mathrm{SL}$ between the cages: estimated mean $\mathrm{SL}^{\circ}(95 \% \mathrm{Cl})$.

\begin{tabular}{lccc}
\hline & $\mathbf{6}^{\circ}$ Cage & $\mathbf{1 0}^{\circ}$ Cage & $\mathbf{1 2}^{\circ}$ Cage \\
\hline Preop & $6.2(4.0-8.5)$ & $7.8(4.8-10.7)$ & $12.8(10.0-15.6)$ \\
Immediate postop & $9.3(7.0-11.5)$ & $15.2(12.2-18.2)$ & $17.6(14.8-20.4)$ \\
6-month postop & $10.3(8.0-12.6)$ & $13.4(10.4-16.4)$ & $17.7(14.8-20.5)$ \\
Last follow-up & $8.5(6.1-10.9)$ & $13.9(10.6-17.1)$ & $18.7(15.8-21.7)$
\end{tabular}

Abbreviations: CI, confidence interval; postop, postoperative; preop, preoperative; SL, segmental lordosis.
CI: $\left.2.9^{\circ}-14.0^{\circ} ; P=.068\right)$, no statistically significant change in LL was detected from preop to last follow-up $\left(45.7^{\circ}, 6.0^{\circ}\right.$ increase, $95 \% \mathrm{CI}:-0.6^{\circ}$ to $12.6^{\circ} ; P=.075$ ) (Tables 4 and 5).

Furthermore, the $12^{\circ}$ cage was used in 20 patients (33 levels) as illustrated in Table 1. Ten, six, and four patients underwent a 1-, 2-, and 3-level LLIF, respectively (Table 1). Ten patients received concurrent posterior pedicle screw fixation. Two patients received L4-S1 ALIF cages in addition to $12^{\circ}$ LLIF cages at the index levels (these levels were excluded from analyses). In this cohort, the mean preop, immediate postop, 6-month postop, and last follow-up SLs were recorded as $12.8^{\circ}, 17.6^{\circ}, 17.7^{\circ}$, and $18.7^{\circ}$, respectively (Table 2 ). From preop, there were $4.8^{\circ}$ increase $\left(95 \% \mathrm{CI}: 2.6^{\circ}-7.1^{\circ} ; P=<.0001\right)$ in SL at immediate postop, $4.8^{\circ}$ increase $(95 \% \mathrm{CI}$ : $\left.2.6^{\circ}-7.1^{\circ} ; P=<.0001\right)$ at 6 -month postop, and $5.9^{\circ}$ increase $\left(95 \%\right.$ CI: $\left.3.5^{\circ}-8.3^{\circ} ; P=<.0001\right)$ at last follow-up (Table 3 ). Like the $6^{\circ}$ group, there was no statistically significant difference in estimated LL over time. $L L$ was $46.7^{\circ}$ at preop, $51^{\circ}$ at immediately postop $\left(4.3^{\circ}\right.$ increase, $95 \% \mathrm{CI}$ : $-0.2^{\circ}$ to $8.8^{\circ} ; P=$ $.059), 49.4^{\circ}$ at 6 -month postop $\left(2.7^{\circ}\right.$ increase, $95 \%$ CI: $-1.8^{\circ}$ to $7.2^{\circ} ; P=.234$ ), and $49.0^{\circ}$ at last followup $\left(2.3^{\circ}\right.$ increase, $95 \% \mathrm{CI}$ : $-2.7^{\circ}$ to $\left.7.2^{\circ} ; P=.361\right)$ (Tables 4 and 5).

The model also provided an intercohort comparison at the specific study time points. The mean 
Table 3. Comparison of SL between the cages: estimated mean change in $S L^{\circ}$ from preop.

\begin{tabular}{|c|c|c|c|c|c|c|}
\hline Parameter & $6^{\circ}$ Cage & $10^{\circ}$ Cage & $12^{\circ}$ Cage & p1 & p2 & $\overline{p 3}$ \\
\hline$\Delta 1$ & & & & $.004^{\mathrm{b}}$ & .236 & .115 \\
\hline $\begin{array}{l}\text { Mean }(95 \% \text { CI }) \\
P^{a}\end{array}$ & $\begin{array}{c}3.1(1.3-4.9) \\
.001^{\mathrm{b}}\end{array}$ & $\begin{array}{c}7.4(5.1-9.8) \\
<.0001^{\mathrm{b}}\end{array}$ & $\begin{array}{c}4.8(2.6-7.1) \\
<.0001^{\mathrm{b}}\end{array}$ & & & \\
\hline $\begin{array}{l}\Delta 2 \\
\quad \text { Mean }(95 \% \text { CI })\end{array}$ & $\begin{array}{c}4.1(2.3-5.9) \\
<.0001^{\mathrm{b}}\end{array}$ & $\begin{array}{c}5.6(3.3-8.0) \\
<.0001^{\mathrm{b}}\end{array}$ & $\begin{array}{c}4.8(2.6-7.1) \\
<.0001^{\mathrm{b}}\end{array}$ & .314 & .618 & .632 \\
\hline $\begin{array}{l}\Delta 3 \\
\quad \text { Mean }(95 \% \mathrm{CI})\end{array}$ & $\begin{array}{c}2.3(0.4-4.2) \\
.021^{\mathrm{b}}\end{array}$ & $\begin{array}{c}6.1(3.4-8.8) \\
<.0001^{\mathrm{b}}\end{array}$ & $\begin{array}{c}5.9(3.5-8.3) \\
<.0001^{\mathrm{b}}\end{array}$ & $.025^{\mathrm{b}}$ & $.022^{\mathrm{b}}$ & .632 \\
\hline
\end{tabular}

Abbreviations: $\mathrm{CI}$, confidence interval; $\Delta 1$, mean change at immediate postop; $\Delta 2$, mean change at 6-month postop; $\Delta 3$, mean change at last follow-up; postop, postoperative; preop, preoperative; SL, segmental lordosis

${ }^{\mathrm{a}} P=P$ value $($ versus preop $\mathrm{SL}) ; \mathrm{p} 1, P$ value $\left(6^{\circ}\right.$ versus $\left.10^{\circ}\right) ; \mathrm{p} 2, P$ value $\left(6^{\circ}\right.$ versus $\left.12^{\circ}\right) ; \mathrm{p} 3, P$ value $\left(10^{\circ}\right.$ versus $\left.12^{\circ}\right)$

${ }^{\text {b }}$ Statistical significance at $P<.05$.

change in SL in the $10^{\circ}$ group was significantly larger than that of the $6^{\circ}$ cohort at immediate postop and last follow-up ([7.4 versus 3.1, $P=.004]$, [6.1 versus $2.3, P=.025]$, respectively) (Table 3 ). The $12^{\circ}$ cohort only showed significantly greater mean change in SL compared with the $6^{\circ}$ cohort at last follow-up (5.9 versus 2.3, $P=.022$ ) (Tables 3). However, there was no statistically significant difference in the mean change in SL between the $10^{\circ}$ and $12^{\circ}$ cohorts at all time points $(P=.115, .632$, .917 , respectively) (Table 3 ). When compared with the $6^{\circ}$ cohort, the $10^{\circ}$ cohort did show statistically larger estimated mean change in LL at immediate postop $(P=.006)$, which we believe was probably skewed by the concurrent nonlordotic cages or hyperlordotic cages $\left(20^{\circ}\right.$ and $\left.25^{\circ}\right)$ (Table 5). Otherwise, no significant difference was detected between the cohorts at any other time points (Table 5).

Three patients received concurrent $6^{\circ}$ and $12^{\circ}$ LLIF cages. One patient with prior L4-5 TLIF underwent removal of migrated TLIF cage followed by a L4-5 LLIF with a $6^{\circ}$ cage with favorable outcome. One patient with prior L4-5 LLIF $\left(6^{\circ}\right.$ cage) suffered from persistent severe low back pain secondary to pseudoarthrosis at L4-5 subsequently underwent removal of L4-5 LLIF cage and placement of L4-5 ALIF. Three patients with prior fusion and persistent severe back pain secondary to scoliosis and spondylolisthesis failed nonoperative

Table 4. Comparison of $\mathrm{LL}$ between the cages: estimated mean $\mathrm{LL}^{\circ}(95 \% \mathrm{Cl})$.

\begin{tabular}{lccc}
\hline Characteristics & $\mathbf{6}^{\circ}$ Cage & $\mathbf{1 0}^{\circ}$ Cage & $\mathbf{1 2}^{\circ}$ Cage \\
\hline Preop & $40.3(35.8-44.9)$ & $39.7(32.5-46.8)$ & $46.7(40.9-52.4)$ \\
Immediate postop & $40.5(36.0-45.1)$ & $49.3(42.1-56.4)$ & $51.0(45.2-56.8)$ \\
6-month postop & $42.6(38.0-47.2)$ & $48.2(41.0-55.3)$ & $49.4(43.6-55.1)$ \\
Last follow-up & $43.4(38.6-48.2)$ & $45.7(37.7-53.6)$ & $49.0(42.9-55.1)$ \\
\hline $\begin{array}{l}\text { Abbreviations: CI, confidence interval; LL, lumbar lordosis; postop, } \\
\text { postoperative; preop, preoperative. }\end{array}$
\end{tabular}

management and subsequently underwent LLIFs with favorable outcome.

\section{DISCUSSION}

Lumbar interbody fusion techniques have become a mainstay in the operative treatment of lumbar degenerative disease. Numerous comparative studies have analyzed the differences between lateral, posterior, transforaminal, and anterior interbody fusions in terms of technique and outcomes. ${ }^{7,21-25}$ However, formulating an optimal surgical strategy to treat specific lumbar conditions depends on many important factors, including sagittal realignment segmentally, regionally, and in some cases globally. In this study, we investigated the extent of SL gain using LLIF cages with varying lordotic angulation. Our study shows that cages with higher lordotic angulation $\left(10^{\circ}\right.$ and $\left.12^{\circ}\right)$ demonstrated superior SL gain that was maintained over the follow-up time period compared with standard $6^{\circ}$ lordotic cages. Due to the heterogeneity of surgical procedures and cage types used within any given case, we did not detect a significant difference in LL gain using cages with higher lordotic angle (see Figures 4 and 5).

Although several LLIF studies in the literature have analyzed lordotic correction using different cage dimensions (ie, height, width, or length) or cage angulation, none of these studies quantify the degree of postoperative lordosis gain relative to the lordotic angle of the cage. ${ }^{1,7,11,15,22}$

Depending on the pathology (degenerative disease, deformity, or tumor) and the magnitude of neural element compression, the chosen cage size (dimension and angle) is often patient-dependent. Because the goal of LLIF procedures is to restore normal SL, cages with varying lordotic angle are used anecdotally by different spine surgeons to 
Table 5. Comparison of LL between the cages: estimated mean change in $\mathrm{LL}^{\circ}$ from preop.

\begin{tabular}{|c|c|c|c|c|c|c|}
\hline Parameter & $6^{\circ}$ Cage & $10^{\circ}$ Cage & $12^{\circ}$ Cage & p1 & p2 & p3 \\
\hline$\Delta 1$ & & & & $.006^{\mathrm{b}}$ & .159 & .148 \\
\hline Mean $(95 \% \mathrm{CI})$ & $0.2(-3.3-3.8)$ & $9.6(4.0-15.1)$ & $4.3(-0.2-8.8)$ & & & \\
\hline$P^{a}$ & .900 & $.001^{\mathrm{b}}$ & .059 & & & \\
\hline$\Delta 2$ & & & & .068 & .886 & .112 \\
\hline Mean $(95 \% \mathrm{CI})$ & $2.3(-1.4-6.0)$ & $8.5(2.9-14.0)$ & $2.7(-1.8-7.2)$ & & & \\
\hline$P^{a}$ & .218 & $.003^{\mathrm{b}}$ & .234 & & & \\
\hline$\Delta 3$ & & & & .456 & .803 & .379 \\
\hline Mean $(95 \% \mathrm{CI})$ & $3.1(-0.8-7.2)$ & $6.0(-0.6-12.6)$ & $2.3(-2.7-7.2)$ & & & \\
\hline$P^{a}$ & .116 & .075 & .361 & & & \\
\hline
\end{tabular}

Abbreviations: CI, confidence interval; $\Delta 1$, mean change at immediate postop; $\Delta 2$, mean change at 6-month postop; $\Delta 3$, mean change at last follow-up; LL, lumbar lordosis; postop, postoperative; preop, preoperative.

${ }^{\mathrm{a}} P=P$ value (versus preop $\left.\mathrm{LL}\right) ; \mathrm{p} 1, P$ value $\left(6^{\circ}\right.$ versus $\left.10^{\circ}\right) ; \mathrm{p} 2, P$ value $\left(6^{\circ}\right.$ versus $\left.12^{\circ}\right) ; \mathrm{p} 3, P$ value $\left(10^{\circ}\right.$ versus $\left.12^{\circ}\right)$

${ }^{\text {b }}$ Statistical significance at $P<.05$.

achieve desirable SL. In fact, radiographic analysis comparing $10^{\circ}$ lordotic to nonlordotic cages in LLIF in 1 study showed significantly greater increase in SL with a $10^{\circ}$ cage at 6-weeks' postoperative time, although neither cage showed significant change in global LL. ${ }^{15}$ Overall, our results demonstrated that significant increase in mean SL may be achieved using cages with higher lordotic angle, which is consistent with several other studies in the literature irrespective of the methodologies used in measuring SL. ${ }^{1,2,13-15,22,24-26} \mathrm{We}$ demonstrated significantly improved SL with all lordotic cages at any time point (Figure 2). The magnitude of segmental lordotic gain with using the $10^{\circ}$ cage was significantly greater than the $6^{\circ}$ cage at immediate postop (Figure 3). Similarly, the magnitude of segmental lordotic gain with either $10^{\circ}$ or $12^{\circ}$ cage was significantly greater than the $6^{\circ}$ case at last follow-up (Figure 3).

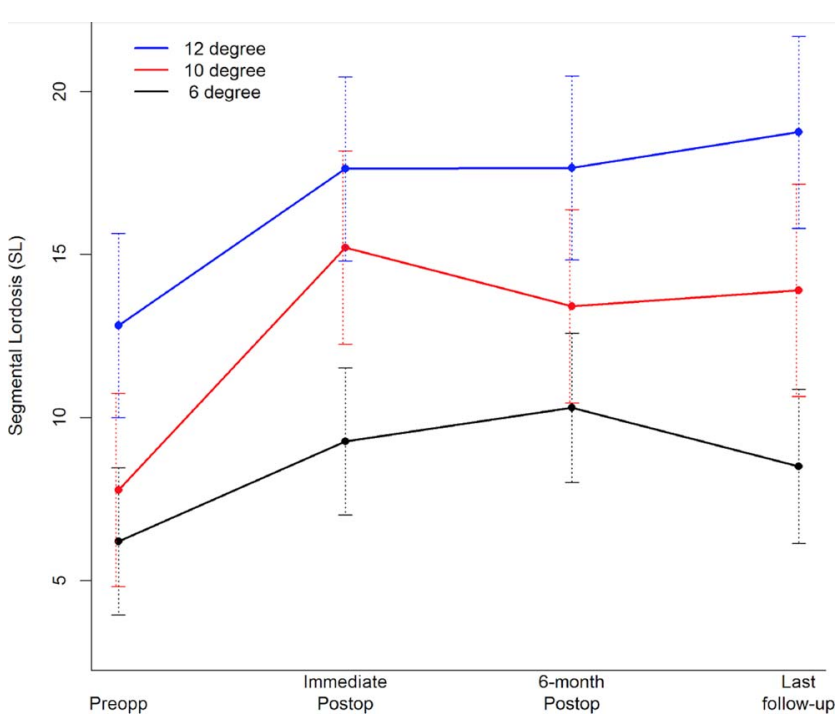

Figure 2. Follow-up time plot depicting mean segmental lordosis (SL) preop, immediately postop, at the 6-month postop, and the last follow-up. Error bars correspond to $95 \%$ Cls.
With regards to global spine alignment, we observed a significant increase in mean LL in the $10^{\circ}$ cohort at immediate and 6-month postop (Figure 4). Also, when compared with the $6^{\circ}$ cohort at immediate postop, the $10^{\circ}$ cohort did show significant higher mean change in LL from preop (Figure 4). However, these observed increases are confounded by the fact that some of the patients in $10^{\circ}$ cohorts also received $20^{\circ}$ or $25^{\circ}$ cages at certain levels. Also, many of our cases were 1-level or 2level LLIF. As such, the contributions of individual SL gain at 1 or 2 levels would not be expected to alter the overall LL. In that regard, it is difficult to derive meaningful inferences from the lack of statistically significant changes in LL irrespective of the cage implant used after surgery (Figure 4) and

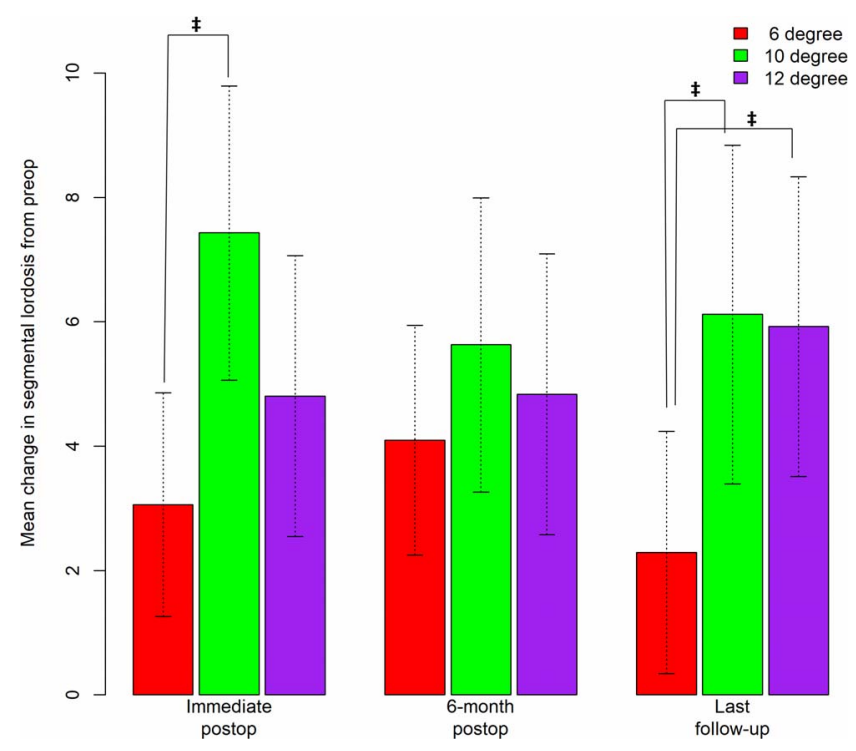

Figure 3. Bar graph depicting mean change in segmental lordosis (SL) from preop to immediate postop, 6-month postop, and the last follow-up. Error bars correspond to $95 \%$ Cls. ¥ indicates statistical significance in increase in mean change in SL from preop to immediate postop between the $6^{\circ}$ and $10^{\circ}$ cage $\left(3.06^{\circ}\right.$ versus $\left.7.43^{\circ}, p=.0041\right)$ and mean change in SL from preop to last followup between the $6^{\circ}$ and $10^{\circ}$ cage $\left(2.30^{\circ}\right.$ versus $\left.6.12^{\circ}, p=.0253\right)$ and between the $6^{\circ}$ and $12^{\circ}$ cage $\left(2.30^{\circ}\right.$ versus $\left.5.93^{\circ}, p=.0219\right)$. 


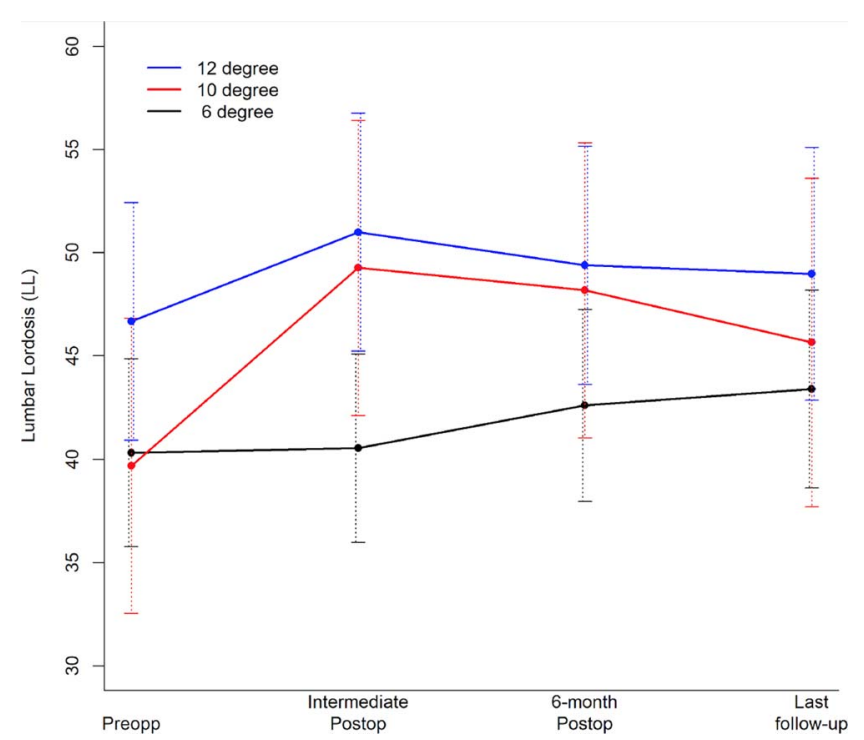

Figure 4. Follow-up time plot depicting mean lumbar lordosis (LL). Error bars correspond to $95 \%$ Cls. No significant change in mean LL at any point of the follow-up.

may also be a factor in similar results observed in several other studies in the literature. , 12,14,22,26 $^{2}$

The lack of correlation between changes in SL and LL can also be explained in part by the fact that standard LL varies over a wide range $\left(44^{\circ}-62^{\circ}\right)$ and normal SL varies by level starting at $2.6^{\circ}-4^{\circ}$ at L1-2 and increasing at each subsequent lumbar level with a maximal SL of $20.2^{\circ}-24^{\circ}$ at L5-S1. ${ }^{26,27}$ Sembrano et $\mathrm{al}^{23}$ speculated a compensatory change in which incremental gain in SL at the index level is cancelled out by loss at adjacent levels resulting in zero change in overall LL. Though a different methodology was used in calculating SL, Pesenti et $\mathrm{al}^{27}$ reported heterogeneous distribution of lordosis throughout the entire lumbar spine such that $62 \%$ of lordosis is derived from the L4-S1 levels. Because the most frequently treated level in this study was L3 -4 , followed by L4 -5 and L2 -3 , the cumulative effect of SL at 1 or 2 levels had insufficient impact on the overall LL. Therefore, to significantly increase LL, we theorize that cages of higher lordotic angles $\left(\geq 12^{\circ}\right)$ will need to be implanted in distal lumbar segments in carefully selected patients with thorough preoperative surgical planning that should incorporate analyses of the remaining spinopelvic parameters. Also, the standard $6^{\circ}$ cage can only restore the most cephalad lumbar level to a normal state, whereas $10^{\circ}$ or $12^{\circ}$ can further augment LL when used at the cephalad levels if desired.

There is an assumption that the postoperative lordotic correction achieved is equivalent to the

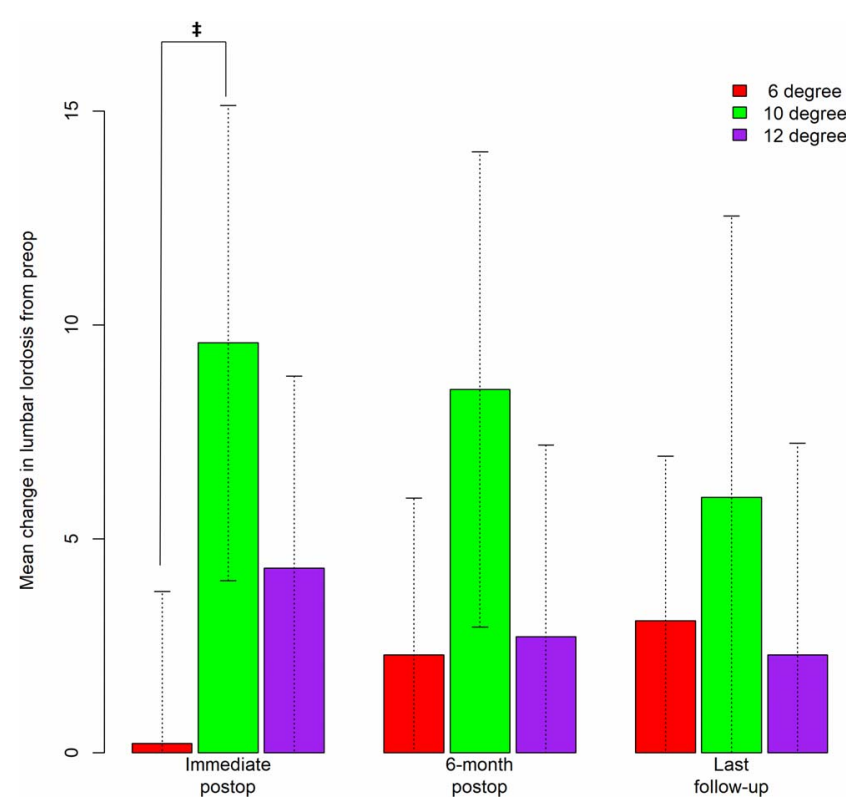

Figure 5. Bar graph depicting predicted mean change in lumbar lordosis (LL) from preop to immediate postop, 6-month postop, and the last follow-up. Error bars correspond to $95 \%$ Cls. Only statistically significant difference exists between the $6^{\circ}$ and $10^{\circ}$ cohort $\left(0.23^{\circ}\right.$ versus $\left.9.58^{\circ}, p=.0057\right)$ at the immediate postop period.

native lordosis of the implant; however, this is not always the case. Potential reasons for less than optimal lordotic correction include graft migration and/or subsidence. Our study showed $5.76 \%$, $6.67 \%$, and $15.2 \%$ subsidence rates for the $6^{\circ}, 10^{\circ}$, and $12^{\circ}$ groups, respectively. We believe that a larger patient sample size, especially in the $10^{\circ}$ and $12^{\circ}$ groups, may have resulted in lower subsidence rates than reported here. Some of the factors contributing to subsidence reported in the literature included technique and experience, implant material, bone quality, cage dimension, and degree of bone remodeling with change in spine biomechanics after cage implantation and/or excessive decortication of the endplate. ${ }^{2,28}$ Because we did not stratify based on any of aforementioned factors, it is difficult to interpret subsidence rates within the context of this study. Tempel et $\mathrm{al}^{28}$ reported $8.7 \%$ subsidence rate in patients with DEXA $T$-score $<-1.0$ who underwent stand-alone LLIF, $48 \%$ of which required augmentation with posterior instrumentation. One study reported increased subsidence in stand-alone LLIF using standard $(18 \mathrm{~mm})$ compared with wide cage $(22 \mathrm{~mm})$ illustrating the importance of cage width in reducing subsidence. ${ }^{13}$ Similarly, several other studies have reported significant decrease in subsidence rate with wider cages. $^{6,12,29}$ In a systematic review pooling 21 articles and a total of 1362 patients, the incidence 
of subsidence in LLIF was reported to be $10.3 \%$ and only $2.7 \%$ resulted in reoperation. ${ }^{30}$ Kotwal et $\mathrm{al}^{1}$ reported cage subsidence in 34 out of total 237 levels operated on. Although most of the cases of subsidence we reported in our study were radiographically subtle and asymptomatic, 1 patient with prior stand-alone LLIF suffered from severe subsidence resulting in re-stenosis that necessitated further decompression and instrumented fusion.

\section{Limitations}

Our study is limited by the retrospective nature of the data analysis introducing inherent biases. Also, postoperative computed tomography imaging might have provided more accurate determination of degrees of subsidence; however, this imaging modality was not routinely performed on these patients at follow-ups. Variability in Cobb angle measurement could have inadvertently introduced measurement error as well. The number of levels analyzed may have limited the power of this study. Also, the last follow-up time is not uniform and may have skewed the result as well. For example, cohorts were not stratified based on stand-alone versus pedicle screw augmentation due to the limited number of patients who would need to be included in each stratum.

Another limitation of this study was overall follow-up rate of $70 \%$ owing to patient compliance, tertiary referral patterns in the Chicago area, and patients choosing to follow locally. That said, we utilized a linear mixed effects model to estimate the mean trend in this longitudinal data set with slightly skewed data. All patients have preop and immediate postop radiographs. Although patients who were missing both 6-month and last follow-up radiographs were eliminated from this study, we included patients with at least 6-month follow-up radiographs.

\section{CONCLUSION}

Overall, our study illustrates that application of $6^{\circ}, 10^{\circ}$, or $12^{\circ}$ cages during LLIF procedures can significantly improve SL that is maintained over time. However, the magnitude of SL achieved with the implantation $10^{\circ}$ or $12^{\circ}$ cage is greater than with the $6^{\circ}$ cage. By confirming these anatomic results radiographically, these data may serve as a guide when planning lumbar interbody reconstructive procedures. Specifically, degree of cage lordosis selection likely needs to be tailored to each of the levels being treated (eg, L1-2 versus L4-5), patientspecific anatomy, and the overall goals of the surgical procedure including total amount of desired lordosis correction segmentally, regionally, and globally.

\section{ACKNOWLEDGMENTS}

The authors express their gratitude to Todd Beck, MS, a statistician from our institution Bioinformatics and Biostatistics Core, who assisted tremendously with the statistical analyses. This research was reviewed and approved by the Institutional Review Board at Rush University Medical Center.

\section{REFERENCES}

1. Kotwal S, Kawaguchi S, Lebl D, et al. Minimally invasive lateral lumbar interbody fusion: clinical and radiographic outcome at a minimum 2-year follow-up. J Spinal Disord Tech. 2015;28(4):119-125.

2. Malham GM, Ellis NJ, Parker RM, et al. Maintenance of segmental lordosis and disk height in stand-alone and instrumented extreme lateral interbody fusion (XLIF). Clin Spine Surg. 2017;30(2):E90-E98.

3. McGowan JE, Kanter AS. Lateral approaches for the surgical treatment of lumbar spondylolisthesis. Neurosurg Clin N Am. 2019;30(3):313-322.

4. Park P. Three-dimensional computed tomography-based spinal navigation in minimally invasive lateral lumbar interbody fusion: feasibility, technique, and initial results. Neurosurgery. 2015;11(suppl 2):259-267.

5. Pawar A, Hughes A, Girardi F, et al. Lateral lumbar interbody fusion. Asian Spine J. 2015;9(6):978-983.

6. Salzmann SN, Shue J, Hughes AP. Lateral lumbar interbody fusion-outcomes and complications. Curr Rev Musculoskelet Med. 2017;10(4):539-546.

7. Xu DS, Bach K, Uribe JS. Minimally invasive anterior and lateral transpsoas approaches for closed reduction of grade II spondylolisthesis: initial clinical and radiographic experience. Neurosurg Focus. 2018;44(1):E4.

8. Ozgur BM, Aryan HE, Pimenta L, Taylor WR. Extreme lateral interbody fusion (XLIF): a novel surgical technique for anterior lumbar interbody fusion. Spine J Off J North Am Spine Soc. 2006;6:435-443.

9. Campbell PG, Nunley PD, Cavanaugh D, et al. Shortterm outcomes of lateral lumbar interbody fusion without decompression for the treatment of symptomatic degenerative spondylolisthesis at L4-5. Neurosurg Focus. 2018;44(1):E6.

10. Cole CD, McCall TD, Schmidt MH, Dailey AT. Comparison of low back fusion techniques: transforaminal lumbar interbody fusion (TLIF) or posterior lumbar interbody fusion (PLIF) approaches. Curr Rev Musculoskelet Med. 2009;2(2):118-126.

11. Joseph JR, Smith BW, Patel RD, Park P. Use of 3D CTbased navigation in minimally invasive lateral lumbar interbody fusion. J Neurosurg Spine. 2016;25(3):339-344. 
12. Kim SJ, Lee YS, Kim YB, et al. Clinical and radiological outcomes of a new cage for direct lateral lumbar interbody fusion. Korean J Spine. 2014;11(3):145-151.

13. Marchi L, Abdala N, Oliveira L, et al. Radiographic and clinical evaluation of cage subsidence after stand-alone lateral interbody fusion. J Neurosurg Spine. 2013;19(1):110-11 8.

14. Scherman DB, Rao PJ, Phan K, et al. Outcomes of direct lateral interbody fusion (DLIF) in an Australian cohort. $J$ Spine Surg. 2019;5(1):1-12.

15. Sembrano JN, Horazdovsky RD, Sharma AK, et al. Do lordotic cages provide better segmental lordosis versus nonlordotic cages in lateral lumbar interbody fusion (LLIF)? Clin Spine Surg. 2017;30(4):E338-E343.

16. Chang Y, Singer DE, Wu YA, Keller RB, Atlas SJ. The effect of surgical and nonsurgical treatment on longitudinal outcomes of lumbar spinal stenosis over 10 years. J Am Geriatr Soc. 2005;53(5):785-792.

17. Choi YH, Kwon SW, Moon JH, et al. Lateral lumbar interbody fusion and in situ screw fixation for rostral adjacent segment stenosis of the lumbar spine. J Korean Neurosurg Soc. 2017;60(6):755-762.

18. Delitto A, Piva SR, Moore CG, et al. Surgery versus nonsurgical treatment of lumbar spinal stenosis: a randomized trial. Ann Intern Med. 2015;162(7):465-473.

19. Panchal R, Denhaese R, Hill C, et al. Anterior and lateral lumbar interbody fusion with supplemental interspinous process fixation: outcomes from a multicenter, prospective, randomized, controlled study. Int J Spine Surg. 2018;12(2):172184.

20. Pretz CR, Graham JE, Middleton A, Karmarkar AM, Ottenbacher KJ. Longitudinal investigation of rehospitalization patterns in spinal cord injury and traumatic brain injury among Medicare beneficiaries. Arch Phys Med Rehabil. 2017;98(5):9971003.

21. Liu J, Deng H, Long X, et al. A comparative study of perioperative complications between transforaminal versus posterior lumbar interbody fusion in degenerative lumbar spondylolisthesis. Eur Spine J. 2016;25(5):1575-1580.

22. Saadeh YS, Joseph JR, Smith BW, et al. Comparison of segmental lordosis and global spinopelvic alignment after single-level lateral lumbar interbody fusion or transforaminal lumbar interbody fusion. World Neurosurg. 2019;126:e1374e1378.

23. Sembrano JN, Tohmeh A, Isaacs R. SOLAS Degenerative Study Group two-year comparative outcomes of mis lateral and mis transforaminal interbody fusion in the treatment of degenerative spondylolisthesis: part I: clinical findings. Spine. 2016;41(suppl 8):S123-S132.

24. Teng I, Han J, Phan K, Mobbs R. A meta-analysis comparing ALIF, PLIF, TLIF and LLIF. J Clin Neurosci. 2017:44:11-17.

25. Yan DL, Pei FX, Li J, Soo CL. Comparative study of
PILF and TLIF treatment in adult degenerative spondylolisthesis. Eur Spine J. 2008;17(10):1311-1316.

26. Le TV, Vivas AC, Dakwar E, et al. The effect of the retroperitoneal transpsoas minimally invasive lateral interbody fusion on segmental and regional lumbar lordosis. ScientificWorldJournal. 2012;2012:516706.

27. Pesenti S, Lafage R, Stein D, et al. The amount of proximal lumbar lordosis is related to pelvic incidence. Clin Orthop Relat Res. 2018;476(8):1603-1611.

28. Tempel ZJ, Gandhoke GS, Okonkwo DO, Kanter AS. Impaired bone mineral density as a predictor of graft subsidence following minimally invasive transpsoas lateral lumbar interbody fusion. Eur Spine J. 2015;24(suppl 3):414 419.

29. Le TV, Baaj AA, Dakwar E, et al. Subsidence of polyetheretherketone intervertebral cages in minimally invasive lateral retroperitoneal transpsoas lumbar interbody fusion. Spine. 2012;37:1268-1273.

30. Macki M, Anand SK, Surapaneni A, et al. Subsidence rates after lateral lumbar interbody fusion: a systematic review. World Neurosurg. 2019;122:599-606.

Disclosures and COI: Dr Fontes is a consultant for Globus Medical. Dr Fessler is a consultant for DePuy Synthes, receives royalties from DePuy Synthes, and has co-ownership in In Queue Innovations. Dr O'Toole is a consultant for Globus Medical, receives royalties from Globus Medical, receives royalties from RTI Surgical, and has stock ownership in TheraCell, Inc. The other authors received no funding for this study and report no conflicts of interest.

Corresponding Author: John E. O'Toole, MD, MS, Rush University Medical Center, Department of Neurosurgery, Rush Professional Office Building, 1725 W Harrison St, Suite 855, Chicago, IL 60612. Phone: (312) 942-6644; Email: john_otoole@rush.edu.

Published 1 June 2021

This manuscript is generously published free of charge by ISASS, the International Society for the Advancement of Spine Surgery. Copyright (C) 2021 ISASS. To see more or order reprints or permissions, see http://ijssurgery.com. 